\title{
Nietzsche y Ortega
}

\author{
JESÚS CONILL
}

\section{NieTzSCHE DESDE EL '98 ESPAÑOL}

Nietzsche comienza a entrar en España en una época de crisis histórica, que coincide culturalmente con la denominada 'Generación del '98'1. Como nos ha recordado Laín Entralgo, las crisis históricas se producen por el advenimiento de cambios profundos en las ideas y sobre todo en las creencias que configuran un determinado mundo, porque son ellas en lo que se está y con lo que se cuenta para llevar adelante la propia vida².

La inspiración nietzscheana es apreciable en el contexto literario, político y social del '98 español; pero, a mi juicio, no debe pasar desapercibida su relevancia filosófica. Lo que ocurre es que el interés por la filosofía del '98 tiene diversos y peculiares registros, de los que voy a destacar dos, que constituyen valiosas aportaciones al pensamiento contemporáneo, en gran parte debido a la influencia de Nietzsche, y cuya trascendencia llega hasta Ortega, quien los transformará y reorientará de un modo magistral:

1 Cf. U. Rukser, Nietzsche in der Hispania, Bern/München, Francke, 1962; G. Sobejano, Nietzsche en España, Madrid, Gredos, 1967.

2 P. Laín Entralgo, Esperanza en tiempo de crisis, Barcelona, Círculo de Lectores/Galaxia Gutenberg, 1993. 
$\left.1^{\circ}\right)$ La práctica de una filosofía literariáa que supone un peculiar acercamiento a la realidad a través primordialmente de la literatura (una expresión de la vinculación entre pensar y poetizar).

$2^{\circ}$ ) Su aportación a una filosofía del sentimiento, que responde al fracaso epocal de la razón y que va a contribuir decididamente a la formación de una nueva noción de razón. En especial, hay que destacar la revelación del sentimiento trágico de la vida, que sitúa el pensamiento primordialmente en el orden experiencial ${ }^{4}$.

En principio, como señala Julián Marías', a la Generación del '98 hay que agradecerle que superara el desnivel que arrastraba la cultura española respecto de la europea durante todo el siglo XIX. Ésta fue su misión histórica, pues con ella comienza una nueva época: nuestra época actual.

Por otro lado, no debe confundirnos el carácter primordialmente literario de los representantes de la generación del '98, ya que es ésta una forma de aproximación vital a los temas, por la que se logró en España una 'reapropiación' de la vida intelectual. En este sentido, hay que destacar la trascendencia que tuvo la nueva capacidad expresiva del lenguaje de la Generación del '98. Sus innovaciones literarias enriquecieron la sensibilidad para captar la realidad. Tal vez esta forma literaria de recuperar la vida intelectual en la España de la Generación del '98 estuviera motivada en gran parte por la situación en que se encontraba entonces, a fines del siglo XIX, la filosofía y el pensamiento europeo en general. Esto explicaría su afán por prescindir de la teoría como tal, en un tiempo en que en el pensamiento europeo predominaban ciertas tendencias que fomentaban la 'desorientación' o incluso la desesperación de la razón.

3 Según Melchor Fernández Almagro, Vida y literatura de Valle-Inclán, Madrid, 1943, p. 54 (citado por P. Laín, La generación del '98, Madrid, Espasa-Calpe, 1997, p. 65).

4 Ortega aprovechará en su raciovitalismo aspectos de carácter genealógico, fenomenológico, hermenéutico, pragmático, y noológico; cf. J. Conill, «Concepciones de la experiencia», Diálogo filosófico, 41 (1998), 148-170.

5 J. Marías, Ortega, circunstancia y vocación, Madrid, Revista de Occidente, 1973, vol. I; Miguel de Unamuno, Madrid, 1943. 
El pensamiento europeo de la época estaba viviendo ya una crisis del positivismo y en este contexto es como se puede entender el fenómeno del 'irracionalismo', como salida desesperada del angostamiento de la razón.

Se prepara así un giro innovador en la filosofía: de la razón a la vida. Pues pensadores como Kierkegaard, Nietzsche, Bergson, Spengler, Unamuno y Machado no dejaron que la razón suplantara la experiencia de la vida y de la historia. De ahí arranca cierto 'irracionalismo', que no fue una renuncia a entender, sino una negativa a aceptar que entender sea simplemente explicar, puesto que también es posible entender intuyendo y comprendiendo.

Como espléndidamente nos recuerda Laín, «a fines del siglo XIX es sustituida la antigua fe de los hombres en su razón por una entusiasta afirmación de la vida portadora de esa razón humana, una vida que en modo alguno podría ser reducida a razones (sólo en el siglo XX se intentará el penoso esfuerzo de dar expresión a las posibles 'razones' de la 'vida')»6.

Los pensadores del '98 español se apercibieron ya de las insuficiencias del positivismo y del cientificismo, al que habían estado sometidas las mentes de generaciones anteriores, y se abrieron al nuevo espíritu de la época, para el que, como expresa Laín: «La vida es superior e irreductible a la razón, el sentimiento superior a la lógica, la sinceridad más valiosa que la consecuencia» 7 . Porque lo que realmente importa es «la actividad no racional de la vida humana — pasión, voluntad, sentimiento, sensibilidad, inefable emoción».

Pues la actitud positivista y cientificista, en cambio, 'mata la vida'. Por eso, Unamuno, con espíritu nietzscheano afirmaba: « ¿Ideas verdaderas y falsas, decís? Todo lo que eleva e intensifica la vida refléjase en ideas verdaderas, que lo son en cuanto lo reflejen, y en ideas falsas todo lo que la deprime y amengüe... Vivir verdad es más hondo que tener razón» 8 .

6 P. Laín Entralgo, La generación del '98, p. 149. A mi juicio, con los términos 'razones de la vida' es clara la implícita alusión, al menos en la filosofía española, a Ortega y sus discípulos, a los que el mismo Laín se siente estrechamente vinculado.

7 Ibid., p. 150. El subrayado es nuestro.

8 M. de Unamuno, Obras completas, vol. I, p. 958. De ahora en adelante OC. 


\section{El SENTIMIENTO TRÁGICO DE LA VIDA}

Cabe detectar una vía de incorporación del espíritu nietzscheanao en el pensamiento de Unamuno, quien vivió la experiencia de una 'desesperación sentimental', una profunda 'congoja', que se formulará en último término como 'sentimiento trágico de la vida'. En su 'estilo agónico', de pasión y lucha, se refleja el trasfondo desesperado, que forma parte del tipo de vida característico de nuestro tiempo, se le llame 'nihilismo' o 'nadismo', pues lo que en el fondo estos términos quieren revelar es el nivel experiencial — tantas veces reprimido por las racionalizaciones modernas- del 'sentimiento trágico de la vida'.

Como a Nietzsche, la crisis le hizo recapacitar, en primer lugar, sobre las insuficiencias del intelectualismo (manifiesto en el racionalismo e idealismo modernos) para dar cuenta del sentido de la vida y sobre la necesidad de abrirse a los «valores del sentimiento» y al «cultivo de la voluntad»; y, en segundo lugar, le impulsó a desenmascarar la superstición del progreso, ya que el progresismo de la civilización moderna produce «el fruto desabrido y estéril del deseo sin esperanza»9.

No obstante, ni la experiencia de la desesperación como desolación y agonía, ni la experiencia de lo trágico en Unamuno y en Nietzsche están reñidas con toda posible esperanza. De ahí que la esperanza unamuniana — como la nietzscheana— pueda calificarse, a mi juicio, de trágica ${ }^{10}$.

Con su actitud trágica Unamuno y Nietzsche se enfrentan tanto a las pretensiones indebidas de la ciencia positiva como al pensamiento idealista, en la medida en que tanto la ciencia como el idealismo olvidan o relegan al 'hombre de carne y hueso', que es lo que constituye precisamente su punto de partida.

De este modo, el pensamiento trágico introduce una forma de existencia, que se opone al optimismo y al pesimismo, en virtud de un

9 M. de Unamuno, OC III, p. 775. «Nuestros progresistas [...] viven, en el fondo, de una mentira, tratando de ahogar el sentimiento trágico de la vida» (OC VII, p. 187). Ortega incorporará -pero transformados- estos impulsos radicales en su nueva versión de la razón vital.

10 O, según Laín, de agónica (Esperanza en tiempo de crisis, pp. 64-66). 
instinto de libertad creativa. Con Nietzsche se nos abre la experiencia trágica de abismo ${ }^{11}$.

Desde esta inspiración trágica queda abierto, así, un nuevo horizonte para la filosofía, en el que se situará Ortega (con su búsqueda de las razones de la vida), en virtud de las tendencias epocales que conducen a rebasar la razón en nombre de la vida, ya sea sustituyendo las exigencias de la razón por las de la vida, o bien enraizando la razón en la vida. Porque la verdadera tarea de la filosofía no es 'concebir' racionalmente 'lo que es', sin antes haberse dejado empapar por lo que se siente en virtud de las contradicciones de la vida. Un pensamiento vital exige pensar 'con todo el cuerpo' y sólo desde la perspectiva de la vida puede hacerse auténtica filosofía12; cualquier otra cosa es erudición pedante, 'filosofería', pues la filosofía es una cuestión del hombre que vive sin otra alternativa la tragedia de su propia vida ${ }^{13}$.

\section{CONFLICTO ENTRE LA RAZÓN Y LA VIDA}

En una atmósfera de resonancias nietzscheanas, la perspectiva que recibe Ortega a través de Unamuno es que la razón y el sentimiento están en guerra, en trágico conflicto; porque la vida no puede someterse a la razón. Y — claro está- a un filósofo este conflicto entre la razón y la vida le produce una seria incertidumbre, que es algo más que una mera duda metódica, como la cartesiana, pues ésta es la duda de uno que hace como que duda sin dudar. En cambio, la duda de inspiración nietzscheana es profundamente vital, abunda en el persistente conflicto entre las fuerzas de la razón y las del sentimiento.

Pues, si la razón era incapaz de afrontar los temas que emergían como los más auténticos problemas de la época, a saber, la vida y la historia, esto justificaba que la razón entrara en crisis y debiera ser rebasada por la vía del sentimiento y de la vida. Y, entonces, se plantea la cuestión de si hay que optar a favor del irracionalismo, la 'razón de la sinrazón', o bien de una 'reforma de la razón'14.

11 J. Conill, El crepúsculo de la metafísica, Barcelona, Anthropos, 1988, pp. 154 ss.

12 Ibid., pp. 19 y 30. Compárese con la defensa nietzscheana del «cuerpo como hilo conductor» (cf. J. Conill, El poder de la mentira, cap. IX).

13 J. Conill, El enigma del animal fantástico, Madrid, Tecnos, 1991, pp.103-105.

14 P. Garragorri, La filosofía española en el siglo XX, Madrid, Alianza, 1985. 
Es innegable que, en un primer momento, situar el nuevo punto de partida de la filosofía en el hombre concreto, 'de carne y hueso', por tanto, no sólo en la razón, sino en la voluntad, el sentimiento, el cuerpo entero, en la amalgama de lo vital y lo racional, es decir, basar la filosofía en el sentimiento trágico de la vida, produjo una crisis de confianza en la razón, en la medida en que 'la razón' era considerada 'enemiga de la vida'.

Pero también es cierto que esta experiencia —en versión unamuniana- del sentimiento trágico de la vida, de innegables resonancias nietzscheanas, fue uno de los aspectos de la 'filosofía' de Unamuno más criticados por Ortega y Gasset. Pues Ortega opuso a la presunta exclusividad del 'sentimiento trágico de la vida' un 'sentido deportivo y festival' de la existencia. La vida es la unidad radical de esas dos dimensiones (desesperación y fiesta, angustia y deporte). «La vida es angustia y entusiasmo y delicia y amargura e innumerables otras cosas». Es una realidad de mil nombres, porque originariamente consiste en un cierto sabor o temple (Lebensgefübl, en términos de Dilthey), sabor miriádico: diversos y antagónicos 'sabores', que nos sumergen, eso sí, en un enigma vital ${ }^{15}$. El Mundo no es sólo piélago en que me ahogo sino también playa a que arribo. No sólo 'resistencia' sino también 'asistencia'. Vivimos el mundo, a la vez, como intemperie y hogar. De manera que Ortega confiesa no creer en el 'sentimiento trágico de la vida' como «formalidad última del existir humano». «La vida no es una tragedia»16. A su juicio, la idea del sentimiento trágico de la vida es una 'imaginación romántica', 'arbitraria', incluso un 'tosco melodramatismo', que 'envenenó’ a Kierkegaard y de él pasó a Unamuno y Heidegger ${ }^{17}$.

Todo esto provocó en Ortega un intento de reforma profunda de la razón antes de derrumbarla o arrumbarla definitivamente. Y, a mi juicio, será ésta una de las aportaciones de la labor magisterial de Ortega y de sus discípulos a la filosofía contemporánea.

\section{RAZÓN VITAL}

Es muy difícil dudar de la presencia y el influjo de Nietzsche en Ortega. Lo que ocurre es que existen diversas vías, distintos momen-

15 J. Ortega y Gasset, «El lado dramático de la filosofía», Obras completas, vol. VIII, 293 ss. De ahora en adelante OC.

16 Ibid., p. 299

17 Ibid. 
tos y una amplia gama de registros en los que se perciben y evalúan la presencia y la influencia nietzscheanas.

El joven Ortega se sintió atraído por Nietzsche y ya desde sus primeros escritos queda bien patente su influjo ${ }^{18}$. Algunos han creído descubrir diversas etapas, señalando que sólo en alguna de ellas tuvo importancia Nietzsche para orientar su pensamiento; pero lo cierto es que las citas y las referencias a Nietzsche son frecuentes en toda la obra y que progresivamente ha ido cundiendo la idea de que la influencia de Nietzsche en Ortega ha sido decisiva a lo largo de toda su vida intelectual.

Es probable que los primeros encuentros con Nietzsche fueran a través de Unamuno y de su amigo Ramiro de Maeztu. Más tarde (a partir de 1908 ó 1910), el magisterio de Georg Simmel debió ser significativo para enderezar la interpretación y posibilitar el aprovechamiento de Nietzsche de un modo más 'urbanizado'. Pero lo que está claro es que no hay que esperar a una supuesta influencia de Nietzsche a través de Heidegger. Es más, en el pensamiento de Nietzsche encuentra Ortega inspiración y algunos elementos muy significativos para enfrentarse a Heidegger y abrir una nueva vía filosófica alternativa a la heideggeriana; una vía que será característica de la filosofía española ${ }^{19}$.

\subsection{LA VINCULACIÓN ENTRE RAZÓN Y VIDA}

La filosofía española posterior a la Generación del '98, durante el siglo XX, consiste en gran parte en intentar superar la situación creada por los irracionalismos (por ejemplo, el de algunas filosofías de la vida). Precisamente Ortega se dedicó a elevar la vida intelectual española a un nivel teórico y a incorporar el vitalismo a una nueva versión de la razón; y ésta fue una de sus aportaciones al legado de la Generación del '98. Inspirado en Nietzsche, pero 'urbanizándolo' (saliendo de su 'zona tórrida'), Ortega fue capaz de establecer una intrínseca y fecunda relación entre razón y vida. Por ejemplo, a pesar de su inicial afición por Nietzsche, Ortega en una respuesta a Maeztu confiesa su

18 Los primeros escritos de Ortega contienen ideas que suenan a Unamuno y la mayor parte tiene su paralelo en Aurora y Así habló Zaratustra.

19 Desde Ortega, pasando por Zubiri y Zambrano, hasta Laín y Marías. 
distanciamiento posterior (haber salido de la 'zona tórrida' de Nietzsche). Asimismo es éste uno de los aspectos por los que Ortega se enfrentó a Unamuno, ya que a Ortega no le bastaba con ser un «sentidor o un poeta», como decía Unamuno, sino que se afanó por ligar racionalmente los problemas en un sistema.

A mi juicio, este intento de establecer una radical vinculación entre razón y vida es una de las aportaciones del pensamiento español desde la Generación del '98 hasta la actualidad. Ya Unamuno escribió: «Aspiro a la fusión del pensar y del sentir: a pensar el sentimiento y a sentir el pensamiento» ${ }^{20}$. Y Ortega comentó en alguna ocasión que quizá el destino nos tenía reservado «unir las dos hermanas enemigas: la pasión y la filosofía»; pues era su propósito sumar «la transparencia de la idea y el etremecimiento de la víscera» 21 .

Esta tradición hispana, a partir de la Generación del '98, con Ortega, Zubiri y Zambrano, hasta Laín Entralgo y Marías, ha ofrecido nuevos modos de entender la razón en forma de 'razón vital', 'razón histórica', 'razón poética', 'razón sentiente', 'corporal' y 'esperanzada'. Lo cual supone haber descubierto un nuevo 'horizonte' para la filosofía, en el que el estudio de los estratos más profundos de la razón desvela una nueva forma de entender la realidad y de estar inteligentemente en ella; y en el que, a la vez, se alumbra una nueva metafísica a la altura del creciente conocimiento científico, del arriesgado poder de la tecnologías y del abismo vital a que nos expone la experiencia trágica y nihilista.

\subsection{MUNDO DE LA VIDA Y CULTURA}

En concreto, para pasar del modelo de la razón lógica al de la razón en el mundo de la vida, Ortega se ha inspirado en el enfoque nietzscheano. La hermenéutica genealógica nietzscheana intenta introducirnos en las fuerzas de la vida, para lo cual se rige 'según el hilo conductor del cuerpo', porque cuanto mejor conozcamos el cuerpo, más profundizaremos en la 'experiencia vital': «detrás de tus pensamientos y sentimientos [...] se encuentra un soberano poderoso, un

20 Carta a Ilundáin del 24-5-1899, publicada por Hernán Benítez en El drama religioso de Unamuno, Buenos Aires, 1949, p. 297.

21 J. Ortega y Gasset, OC IX, p. 74. 
sabio desconocido - llámase sí mismo (Selbst). En tu cuerpo habita, es tu cuerpo»22. El cuerpo es un centro de sabiduría y acción, el verdadero centro de gravedad del ser humano, de donde surgen todas las creaciones vitales.

Por esta vía, de inspiración nietzscheana, la fenomenología hermenéutica del raciovitalismo orteguiano rebasa el ámbito de la conciencia y del yo, para acercarnos a una «noción corporal del sujeto» ${ }^{23}$ : «en lugar de 'Yo' se dice primero 'mi carne', 'mi cuerpo', 'mi corazón', 'mi pecho'».

La consideración del mundo de la vida como horizonte queda recogido y profundizado en el ensayo orteguiano por ordenar el mundo desde le punto de vista de la vida ${ }^{24}$. Porque la vida humana es, para Ortega, el fondo último y 'mi vida' constituye un hecho radical, previo a toda biología, a toda ciencia y a toda cultura. Pero «vivir es también mundo» 25 , es tratar con el mundo como horizonte vital. La vida, realidad radical e indubitable, incluye, además del sujeto, el mundo. La vida es lo que somos y lo que hacemos, el vivirse y saberse existiendo en un mundo que nos afecta, donde nos encontramos teniendo que tomar decisiones. De ahí que la vida sea 'preocupación'.

Cuando la vida humana no tiene este tono, entonces «vivir es entregarse a lo unánime, dejar que las costumbres, los prejuicios, los usos, los tópicos se instalen en su interior, los hagan vivir a ellos y tomen sobre sí la tarea de hacerlos vivir». Es aquel modo de vida que está movido por el «afán de ser como los demás, de renunciar a la responsabilidad ante el propio destino, disolviéndolo entre la multitud» 26 .

22 F. Nietzsche, Así habló Zaratustra, Madrid, Alianza, p. 61. Cf. J. Conill, El poder de la mentira, Tecnos, Madrid, 1997, caps. VII-X. Contando con un excelente arsenal de conocimientos científicos Pedro Laín Entalgo ha desarrollado una filosofía del cuerpo hasta reconfigurar una verdadera antropología: El cuerpo bumano (Espasa-Calpe, Madrid, 1989), Cuerpo y alma (Espasa Calpe, Madrid, 1991), Cuerpo, alma y persona (Galaxia Gutenberg/ Círculo de Lectores, Barcelona, 1995), Idea de hombre (Galaxia Gutenberg/Círculo de Lectores, Barcelona, 1996).

23 J. Ortega y Gasset, OC VII, p. 395; cf. J. A. Marina, Teoría de la inteligencia creadora, Barcelona, Anagrama, 1993, p. 362; y J. Conill, El poder de la mentira, cap. IX.

24 J. Ortega y Gasset, OC III, «El tema de nuestro tiempo».

25 J. Ortega y Gasset, OC VII, ¿Qué es filosofía?

26 Ibid., p. 438 
El 'fracaso de la cultura' moderna no tendrá solución mientras no se logre transformarla desde el fondo de las fuerzas vitales de las que se nutre; porque «no hay cultura sin vida». Por tanto, «habría que hacer una genealogía de la cultura». «La cultura nace del fondo viviente del sujeto y es [...] vida sensu stricto, espontaneidad, 'subjetividad'. Poco a poco la ciencia, la ética, el arte, la fe religiosa, la norma jurídica se van desprendiendo del sujeto y adquiriendo consistencia propia, valor independiente, prestigio, autoridad. Llega un momento en que la vida misma que crea todo eso se inclina ante ello, se rinde ante su obre y se pone a su servicio. La cultura se ha objetivado, se ha contrapuesto a la subjetividad que la engendró». Pero «la cultura sólo pervive mientras sigue recibiendo constante flujo vital de los sujetos. Cuando esta transfusión se interrumpe, y la cultura se aleja, no tarda en secarse y hieratizarse. [...] En las épocas de reforma como la nuestra, es preciso [...] fomentar la cultura emergente -0 , lo que es lo mismo, quedan en suspenso los imperativos culturales y cobran inminencia los vitales» 27 .

Es tarea de una 'nueva cultura', 'la cultura de la vida', a partir del mundo de la vida en el sentido orteguiano — inspirado en Nietzsche; 'mundo' que constituye una 'perspectiva', y un componente de la realidad, en definitiva, un 'punto de vista', desde el que hay que reorientar la cultura moderna, si queremos salvar la circunstancia. Porque los procesos modernos de racionalización han suplantado la vida, como si la razón formal y sus mecanismos fueran realmente capaces de configurar 'otra vida'. Pero no es posible salirse del «mar de la vitalidad primaria», ya que en último término «la razón es sólo una forma y función de la vida». Por eso, «el tema de nuestro tiempo consiste en someter la razón a la vitalidad» y presentar las exigencias vitales a la cultura («ante el juez infalible Dionysos»). Se trata de rebasar la razón formal en favor de una 'razón vital' y así descubrir «los valores inmanentes a la vida».

\subsection{Animal fantástico}

Nietzsche se encuentra en el trasfondo de la génesis de la razón vital. Ortega se dejó impregnar por un ambiente en el que había una 
preocupación por encontrar nuevos modos de acceder a la realidad viviente, pero evitando el biologismo y el irracionalismo ${ }^{28}$, en los que parecía incurrir Nietzsche.

La clave se hallaba en la noción de 'vida', un tema indudablemente de moda en su época ${ }^{29}$. Pero la noción orteguiana de vida no puede entenderse en sentido biologista, ni sirve para sustentar ningún irracionalismo. Bajo una muy considerable inspiración nietzscheana, Ortega sostiene una peculiar concepción de la vida, que está muy lejos de la utilitarista y hedonista. La vida no consiste radicalmente en adaptarse al medio, sino en adaptarse el medio para vivir. Porque la vida es en principio creación, experimento creador, como en la concepción nietzscheana. De ahí el sentido 'deportivo' y lúdico que encontramos en Ortega y que, por lo demás, es tan cercano al dionisíaco de Nietzsche. Una nueva concepción de la vida, que se ha ido gestando durante todo el siglo XIX, en la que se descubre la unión de ética y biología en un contexto evolucionista y tal vez sea en los círculos kantianos y también en Nietzsche, donde Ortega percibió la compatibilidad radical entre el evolucionismo y Kant ${ }^{30}$.

La vida se entenderá, en un sentido activo, como voluntad de vida, de 'vida esforzada', a partir de un 'sí mismo' sabio y poderoso, como en Nietzsche. De esta concepción de la vida surge inmediatamente una teoría de los valores, de los valores para la vida, los 'valores vitales'. Pues de la vida emergen valores y perspectivas, como puntos de vista para orientar la acción humana. El carácter perspectivista y valorativo del saber constituye un componente esencial del raciovitalismo: vida y razón forman una unidad de entretejimiento (razón vital y vida racional).

Esta visión de la vida permitirá distinguir 'formas más o menos valiosas de vivir', qué sea una 'vida ascendente' o 'descendente', reactiva, a la baja. He aquí valoraciones y hasta una terminología que recuerda

28 J. Marías, Ortega, circunstancia y vocación, vol. I.

29 C. Morón nos recuerda que siete de los dicisiete artículos de la revista Logos en 1912 contenían en su título la palabra vida o la de cultura en relación con la vida (entre ellos, uno de G. Simmel y otro de H. Rickert, titulado «Valores vitales y valores culturales») (El sistema de Ortega y Gasset, pp. 117-8).

30 J. Ortega y Gasset, OC I, p. 115 y 161; cf. C. Morón, op. cit., pp. 171-2. No debe extrañar, puesto que dentro del enfoque evolucionista, en Nietzsche y Ortega, encontramos un sentido no darwiniano de vida. 
constantemente a Nietzsche. Y en el fondo de esta concepción se encuentra la peculiar animalidad del ser humano, al que tanto Nietzsche como Ortega califican de 'animal fantástico'31. Porque la capacidad más fundamental del ser humano es para ambos pensadores la fantasía.

La razón nace de la fantasía, «la razón no es sino un modo, entre muchos, de funcionar la fantasía» y ésta consiste en «sensaciones liberadas»32. «La única actividad originariamente inteligente, el único 'hacerse cargo' o 'darse cuenta', es la sensación, sobre todo liberada en forma de imaginación»33. El hombre es «un animal que escapa a la animalidad», «representa, frente a todo darwinismo, el triunfo de un animal inadaptado» y «enfermo». Esta condición le provocó una «hiperfunción cerebral», que le llenó de «fantasías», un «mundo imaginario». Por eso «el hombre es el animal fantástico; nació de la fantasía»; y «lo que llamamos razón no es sino fantasía puesta en forma. ¿Hay en el mundo nada más fantástico que lo más racional? ¿Hay nada más fantástico que el punto matemático y la línea infinita y, en general, toda la matemática y toda la física? ¿Hay fantasía más fantástica que eso que llamamos 'justicia' y eso otro que llamamos 'felicidad'?»34.

De entre los muchos lugares de la obra de Ortega, en que puede apreciarse este peculiar vitalismo perpectivista y propulsor de los valores de la vida, en estrecha relación con Nietzsche, destaca El tema de nuestro tiemp $0^{35}$. Aquí se percibe el impulso que va desde El nacimiento de la tragedia hasta El crepúsculo de los ídolos, un impulso dirigido a que la cultura sea vital, a que la razón se supedite a la vida. De modo que, a mi juicio, las bases para la transformación hermenéutica de la razón y su relación con la razón vital se encuentran ya en la vinculación de Ortega con Nietzsche ${ }^{36}$. No hace falta esperar a la mediación heideggeriana.

31 Cf. J. Conill, El enigma del animal fantástico, Tecnos, Madrid, 1991.

32 J. Ortega y Gasset, OC VIII, pp. 160-161.

33 Ibid., p. 162.

34 J. Ortega y Gasset, OC IX, pp. 189-190

35 Cf. G. Sobejano, Nietzsche en España, Madrid, Gredos, 1967; N. R. Orringer, Ortega y sus fuentes germánicas, Madrid, Gredos, 1979.

36 Cf. A. Regalado, El laberinto de la razón: Ortega y Heidegger, Madrid, Alianza, 1990; J. Conill, «La transformación de la fenomenología en Ortega y Zubiri: la postmodernidad metafísica», en Ortega y la fenomenología, Madrid, UNED, 1992, pp. 297-312; para la relación Nietzsche-Ortega referida a la vertiente práctica cf. J. Conill, El poder de la mentira. Nietzsche y la política de la transvaloración, Madrid, Tecnos, 1997, parte III. 